\title{
Early experience with robot-assisted laparoscopic hepatobiliary and pancreatic surgery in Singapore: single-institution experience with 20 consecutive patients
}

Brian KP $\underline{G o h}^{1,2}$, MBBS, FRCSEd, Ser-Yee $\underline{L e}^{1}$, MBBS, FRCSEd, Chung-Yip Chan ${ }^{1}$, MBBS, FRCSEd, Jen-San Wong ${ }^{1}$, MBBch, FRCSEd, Peng-Chung $\underline{\text { Cheow }^{1}}$, MBBS, FRCSEd, Alexander YF $\underline{\text { Chung }^{1}}$, MBBS, FRCSEd, London ${ }^{\text {LJ Ooi }}{ }^{1}$, MBBS, FRCSEd

INTRODUCTION Experience with robot-assisted laparoscopic (RAL) hepatobiliary and pancreatic (HPB) surgery remains limited worldwide. In this study, we report our early experience with RAL HPB surgery in Singapore.

METHODS A retrospective review of the first 20 consecutive patients who underwent RAL HPB surgery at a single institution over a 34-month period from February 2013 to November 2015 was conducted. The 20 cases were performed by three principal surgeons, of which 17 (85.0\%) were performed by a single surgeon.

RESULTS The median age of patients was 56 (range 22-75) years and median tumour size was 4.0 (range 1.2-7.5) cm. The surgeries performed included left-sided pancreatectomies $(n=10)$, hepatectomies $(n=7)$, triple bypass with bile duct exploration for obstructing pancreatic head cancer with choledocholithiasis $(n=1)$, cholecystectomy for Mirizzi's syndrome $(n=1)$ and gastric resection for gastrointestinal stromal tumour $(n=1)$. The median operation time was 445 (range 80-825) minutes and median blood loss was 350 (range 0-1,200) $\mathrm{mL}$. There was only 1 (5\%) open conversion. There were $2(10.0 \%)$ major morbidities (> Grade II on the Clavien-Dindo classification) and no 30-day/in-hospital mortalities. There was no reoperation for postoperative complications. The median postoperative stay was 5.5 (range 3-22) days. CONCLUSION Our initial experience confirms the feasibility and safety of RAL HPB surgery.

Keywords: robotic hepatectomy, robotic hepatobiliary surgery, robotic liver resection, robotic pancreatectomy, robotic pancreatic resection

\section{INTRODUCTION}

Following the introduction of laparoscopic surgery in the late 1980s, the adoption of minimally invasive surgery has rapidly increased in the field of abdominal surgery. ${ }^{(1)}$ In many specialised centres, laparoscopy has become almost routine for simple abdominal surgical procedures, such as appendicectomies ${ }^{(2)}$ and cholecystectomies. ${ }^{(3)}$ Laparoscopic surgery has also been widely adopted for more complex procedures, such as adrenalectomies, ${ }^{(4)}$ gastric resections ${ }^{(5)}$ and colectomies. ${ }^{(6)}$ However, despite its widespread use for various abdominal surgeries, the use of laparoscopy in the field of hepatobiliary and pancreatic (HPB) surgery has been largely limited to cholecystectomies in most centres worldwide. The slow adoption of laparoscopic HPB surgery is mainly due to the technical complexities associated with hepatectomies ${ }^{(1)}$ and pancreatectomies, ${ }^{(7)}$ resulting in concerns about complications from catastrophic haemorrhage and adequacies of oncological margins. ${ }^{(8)}$

Nonetheless, during the past few years, the field of HPB surgery has seen an increase in the adoption of minimally invasive surgery, with the improvement and standardisation of surgical techniques and the development of sophisticated laparoscopic instruments. Numerous studies have shown that laparoscopic hepatectomies $(\mathrm{LHs})^{(9)}$ and laparoscopic pancreatectomies $(\mathrm{LPs})^{(10)}$ can be performed safely in expert centres. Even for complex procedures, the minimally invasive approach seemed to result in the usual advantages, such as decreased pain and shorter hospital length of stay without compromising patient safety and oncological outcomes. ${ }^{(9,10)}$ Nonetheless, despite advances in laparoscopic technology, the inherent limitations of conventional laparoscopy, such as restriction in movement and dexterity due to the rigidity of instruments, tremor amplification and lack of depth perception remain. ${ }^{(11,12)}$ These limitations remain a major obstacle to the application of laparoscopy to complex surgery. One of the major criticisms of laparoscopic HPB surgery is its relatively long learning curve and its lack of universal applicability. ${ }^{(1,8,13)}$

Robot-assisted laparoscopic (RAL) surgery was introduced to overcome the limitations of conventional laparoscopic surgery. It provides a three-dimensional high-definition magnified view of the operative field and additional advantages in terms of improved dexterity and precision with its increased freedom of movement and elimination of tremor. ${ }^{(14,15)}$ However, despite the many theoretical advantages of RAL surgery over conventional laparoscopy, its clinical use remains limited, mainly due to the increased cost associated with this technology. Presently, only a few centres worldwide ${ }^{(16-19)}$ have reported their experiences with RAL HPB surgery.

In Singapore, laparoscopic HPB surgery is a growing field, with the first report of three $\mathrm{LHs}^{(20)}$ and another series of three $\mathrm{LPs}^{(21)}$

${ }^{1}$ Department of Hepatopancreatobiliary and Transplantation Surgery, Singapore General Hospital, ${ }^{2}$ Duke-NUS Medical School, Singapore

Correspondence: A/Prof Brian KP Goh, Associate Professor, Department of Hepatopancreatobiliary and Transplantation Surgery, Singapore General Hospital, 20 College Road, Level 5 Academia, Singapore 169856. bsgkp@hotmail.com 
published in 2009 from Tan Tock Seng Hospital, Singapore. Subsequently, this centre also reported their experience with laparoscopic common bile duct exploration. ${ }^{(22,23)}$ More recently, several larger case series ${ }^{(1,24,25)}$ on $\mathrm{LH}$ and $\mathrm{LP}^{(7,26)}$ from other centres in the country, including our institution, have been reported. However, experience with RAL HPB surgery in Singapore remains extremely limited; the first two reports ${ }^{(27,28)}$ from our centre were only published very recently, in 2016. In the present study, we report our updated experience with the first 20 consecutive RAL HPB surgeries at our institution. This study aimed to determine the feasibility and safety of RAL surgery when applied to complex HPB surgeries. To the best of our knowledge, this is the first reported series of RAL HPB surgery in Southeast Asia.

\section{METHODS}

This was an institutional review board-approved study of the first 20 consecutive patients who underwent RAL HPB surgery with the da Vinci $\mathrm{Si}^{\mathrm{TM}}$ Surgical System (Intuitive Surgical Inc, Sunnyvale, CA, USA) at a single institution during the 34-month period from February 2013 to November 2015. The 20 operations were performed by three principal surgeons, of which 17 (85.0\%) surgeries were performed by a single surgeon (Goh BK). From 2000 to 2015, surgeons at our institution have had a collective experience of more than 2,700 hepatectomies and 1,100 pancreatectomies, including more than $260 \mathrm{LHs}$ and 45 LPs. During the 54-month period from July 2011 to December 2015, the lead author was individually involved in 310 major HPB operations. These included 200 hepatectomies and 72 pancreatectomies, of which 82 procedures were performed using the minimally invasive approach. The first RAL surgery in 2013 was attempted after the surgeon had undergone Intuitive Surgical certification as a console surgeon and had prior experience performing $25 \mathrm{LH}$ and LP surgeries. The first ten RAL surgeries were performed at our institution under an institutional review board-approved clinical trial protocol.

For liver resections, the anatomical location of the lesions and surgical resection were defined according to the Couinaud classification. ${ }^{(29)}$ The difficulty of liver resections was graded according to the scoring system proposed by Ban et al for laparoscopic resections, whereby a score of $1-3$ was graded as low difficulty, 4-6 as intermediate difficulty and 7-10 as high difficulty. ${ }^{(30)}$ For left-sided pancreatectomies, transection of the pancreas to the right of the portal vein was termed a subtotal pancreatectomy. An extended pancreatectomy was defined according to the recent International Study Group of Pancreatic Surgery definition and included any pancreatic resection for a locally advanced cancer that required resection of an adjacent organ, such as the stomach (for left-sided pancreatectomies), colon or a major blood vessel (e.g. the portal vein). ${ }^{(31)}$

In general, patients were considered for robotic resection when they were assessed to be suitable candidates for minimally invasive surgery. The final choice of surgical approach (laparoscopic, robotic or open) was dependent on various factors, including the individual surgeon's preference and patient's choice after a thorough discussion on the benefits and limitations of the various approaches. Cost was a major factor when considering RAL surgery, which generally cost an additional SGD 10,00012,000 at our institution on top of the normal surgical charges.

The operative technique in this series was not standardised and varied between different procedures and surgeons. The technique also evolved as we progressed along the learning curve. In general, our techniques for RAL hepatectomy and RAL pancreatectomy have been described previously. ${ }^{(27,28)}$ For hepatectomies, parenchymal transection was usually performed with the robotic harmonic scalpel and large vascular pedicles were clipped or stapled. In two patients, the laparoscopic Cavitron Ultrasonic Surgical Aspirator (CUSA; Valleylab, Boulder, CO, USA) was used to aid in parenchymal transection. For pancreatectomies, the harmonic scalpel and hook were used for dissection and pancreatic transection was performed using endoscopic staplers and oversewn selectively.

Operative time, including docking time, total operative blood loss, blood transfusion volume and hospital length of stay after surgery were recorded. Postoperative complications were recorded using the Clavien-Dindo classification ${ }^{(32)}$ up to three months after surgery. Any death within 30 days of surgery or during the index hospital stay regardless of duration from surgery was defined as 30-day/in-hospital mortality. Pancreatic fistula was defined and graded according to the International Study Group of Pancreatic Fistula definition. ${ }^{(33)}$ Drain fluid amylase was routinely collected on Postoperative Day 3, and a value more than three times the concentration of serum amylase or $>300 \mathrm{IU} / \mathrm{L}$ was considered as pancreatic fistula. In this study, a Grade A biochemical pancreatic fistula, which was entirely asymptomatic and did not alter a patient's clinical course, was reported but was not considered a morbidity according to the Clavien-Dindo classification.

\section{RESULTS}

During the study period, 20 consecutive patients underwent attempted RAL HPB surgery. Their clinicopathological features are summarised in Tables I and II. Patients were listed in chronological order according to their date of surgery. The clinical features and outcomes of Patients 1-6 and 11-12 have been described previously. ${ }^{(27,28)}$ The operations performed included left-sided pancreatectomies $(n=10)$, hepatectomies $(n=7)$, triple bypass with common bile duct exploration for obstructing pancreatic head cancer with choledocholithiasis $(n=1)$, cholecystectomy for suspected Mirizzi's syndrome $(n=1)$ and gastric resection for gastrointestinal stromal tumour suspected to involve the pancreas $(\mathrm{n}=1)$.

Two patients (Patients 3 and 18) were found to have serous cystic neoplasms on final pathology. Both patients had indeterminate pancreatic cystic neoplasms with worrisome features on preoperative imaging and a potentially malignant neoplasm could not be excluded definitively. Patient 14 presented with vague abdominal symptoms, with no clinical or biochemical evidence of pancreatitis. Cross-sectional imaging demonstrated a large $6.5-\mathrm{cm}$ solitary cystic lesion in the body of the pancreas. She was diagnosed with a mucinous cystic 
Original Article

Table I. Summary of individual patient demographics and clinical outcomes.

\begin{tabular}{|c|c|c|c|c|c|c|c|c|c|c|c|}
\hline No. & $\begin{array}{l}\text { Age }(y r) / \\
\text { gender }\end{array}$ & Preoperative diagnosis & Site & $\begin{array}{l}\text { Tumour } \\
\text { size }(\mathrm{cm})\end{array}$ & Surgical procedure & Final histology & $\begin{array}{c}\text { Closest } \\
\text { resection } \\
\text { margin }(\mathrm{mm})\end{array}$ & $\begin{array}{l}\text { Difficulty } \\
\text { score* }^{*}\end{array}$ & $\begin{array}{c}\text { Operation } \\
\text { time/docking } \\
\text { time (min) }\end{array}$ & $\begin{array}{l}\text { Blood } \\
\text { loss } \\
(\mathrm{mL})\end{array}$ & $\begin{array}{l}\text { Hospital } \\
\text { length of } \\
\text { stay (day) }\end{array}$ \\
\hline 1 & $38 / \mathrm{M}$ & Symptomatic haemangioma & $\mathrm{Sg} \| / \mathrm{III}$ & 7.3 & Left lateral sectionectomy & Cavernous haemangioma & 1 & 6 & $305 / 60$ & 200 & 5 \\
\hline 2 & $53 / \mathrm{M}$ & $\begin{array}{l}\text { Indeterminate lesion } \\
\text { suspicious for HCC }\end{array}$ & Sg V & 2.1 & $\begin{array}{l}\text { Anatomical Sg V resection with } \\
\text { cholecystectomy }\end{array}$ & $\begin{array}{l}\text { Focal nodular } \\
\text { hyperplasia }\end{array}$ & 2 & 6 & $435 / 30$ & 300 & 4 \\
\hline 3 & $64 / F$ & $\begin{array}{l}\text { Indeterminate pancreatic } \\
\text { cystic neoplasm }\end{array}$ & Tail & 2.1 & Spleen-saving vessel-preserving DP & Serous cystic neoplasm & 31 & NA & $540 / 70$ & 300 & 6 \\
\hline 4 & $22 / \mathrm{M}$ & $\begin{array}{l}\text { Solid pseudopapillary } \\
\text { neoplasm }\end{array}$ & Body & 4.5 & Spleen-saving vessel-preserving DP & $\begin{array}{l}\text { Solid pseudopapillary } \\
\text { neoplasm }\end{array}$ & 1 & NA & $350 / 15$ & 200 & 14 \\
\hline 5 & $66 / F$ & $\mathrm{HCC}$ & Sg $I 1 / I I$ & 2.6 & Sg II/III resection & $\mathrm{HCC}$ & 20 & 2 & $155 / 10$ & 50 & 4 \\
\hline 6 & $61 / F$ & PNEN & Tail & 1.2 & Spleen-saving vessel-preserving DP & PNEN & 1 & NA & $300 / 25$ & 50 & 7 \\
\hline 7 & $68 / F$ & VIPoma & Neck, body & 7.5 & STP and splenectomy & VIPoma & 1 & NA & $550 / 30$ & 1,200 & 22 \\
\hline 8 & $49 / M$ & $\begin{array}{l}\text { Gastric GIST encroaching } \\
\text { on pancreas }\end{array}$ & $\begin{array}{l}\text { Posterior } \\
\text { lesser curve }\end{array}$ & 5.0 & Gastric wedge resection & GIST & 2 & NA & $200 / 15$ & 50 & 4 \\
\hline 9 & $70 / F$ & $\begin{array}{l}\text { Advanced pancreatic cancer } \\
+ \text { choledocholithiasis }\end{array}$ & Head & 6.5 & $\begin{array}{l}\text { Triple bypass (Roux-en-Y HJ) }+ \\
\text { CBDE with cholecystectomy }\end{array}$ & Adenocarcinoma & NA & NA & $500 / 60$ & 50 & 7 \\
\hline 10 & $40 / F$ & BD-IPMN & Body & 1.8 & Spleen-saving vessel-preserving DP & $\mathrm{MCN}$ & 2.4 & NA & $455 / 30$ & 400 & 3 \\
\hline 11 & $43 / F$ & Breast liver metastasis & Sg VII & 2.4 & $\begin{array}{l}\text { Extended right posterior } \\
\text { sectionectomy with } \\
\text { cholecystectomy }\end{array}$ & $\begin{array}{l}\text { Metastatic } \\
\text { adenocarcinoma }\end{array}$ & 1 & 10 & $825 / 40$ & 1,200 & 7 \\
\hline 12 & $62 / \mathrm{M}$ & Colorectal liver metastasis & $\mathrm{Sg} V / \mathrm{VI}$ & 2.5 & $\begin{array}{l}\mathrm{Sg} V / \mathrm{VI} \text { resection with } \\
\text { cholecystectomy }\end{array}$ & $\begin{array}{l}\text { Metastatic } \\
\text { adenocarcinoma }\end{array}$ & 8 & 5 & $340 / 30$ & 800 & 5 \\
\hline 13 & $58 / F$ & PNEN & Tail & 6.9 & $\mathrm{DP}+$ splenectomy & PNEN & 1 & NA & $415 / 45$ & 800 & 4 \\
\hline 14 & $32 / F$ & $\mathrm{MCN}$ & Body & 6.5 & $\begin{array}{l}\text { STP + splenectomy + } \\
\text { cholecystectomy }\end{array}$ & Pseudocyst & 20 & NA & $545 / 20$ & 400 & 12 \\
\hline 15 & $68 / \mathrm{M}$ & PNEN & Body & 1.2 & Spleen-saving vessel-preserving DP & PNEN & 43 & NA & $325 / 45$ & 300 & 6 \\
\hline 16 & $50 / F$ & $\begin{array}{l}\text { Complex cystic tumour, } \\
\text { possible cystadenoma }\end{array}$ & $\begin{array}{l}\text { Sg IVa/ } \\
\text { VIII (dome) }\end{array}$ & 4.5 & $\begin{array}{l}\text { Non-anatomical resection Sg IV, } \\
\text { Sg V, Sg VIII }\end{array}$ & Calcified cyst & 1 & 10 & $495 / 20$ & 500 & 4 \\
\hline 17 & $51 / \mathrm{M}$ & Mirizzi’s syndrome & NA & NA & Cholecystectomy & Chronic cholecystitis & NA & NA & $80 / 15$ & 0 & 3 \\
\hline 18 & $55 / F$ & $\begin{array}{l}\text { Worrisome risk cystic } \\
\text { neoplasm }\end{array}$ & Body & 4.0 & STP + splenectomy & Serous cystic neoplasm & 25 & NA & $540 / 45$ & 900 & 6 \\
\hline 19 & $57 / F$ & Gallbladder cancer & NA & 3.2 & $\begin{array}{l}\text { Radical cholecystectomy (Sg IVb/V) } \\
\text { + hilar lymphadenectomy }\end{array}$ & Gallbladder cancer & 14 & 4 & $530 / 10$ & 750 & 4 \\
\hline 20 & $75 / F$ & $\begin{array}{l}\text { Locally advanced } \\
\text { pancreatic cancer } \\
\text { encroaching stomach }\end{array}$ & Body & 5.5 & $\begin{array}{l}\text { STP + splenectomy + gastric } \\
\text { resection }\end{array}$ & $\begin{array}{l}\text { Pancreatic } \\
\text { adenosquamous } \\
\text { carcinoma }\end{array}$ & 10 & NA & $775 / 20$ & 800 & 9 \\
\hline
\end{tabular}

*Scoring was based on Ban et al's classification. ${ }^{\left({ }^{30}\right)}$ BD: branch duct; CBDE: common bile duct exploration; DP: distal pancreatectomy; F: female; GIST: gastrointestinal stromal tumour; HCC: hepatocellular carcinoma; HJ: hepaticojejunostomy; IPMN: intraductal papillary mucinous neoplasm; M: male; MCN: mucinous cystic neoplasm; NA: not available; PNEN: pancreatic neuroendocrine neoplasm; Sg: segment; STP: subtotal pancreatectomy; VIPoma: vasoactive intestinal peptide tumour 
Table II. Clinicopathological features and outcomes of patients who underwent robot-assisted laparoscopic hepatobiliary and pancreatic surgery $(n=20)$.

\begin{tabular}{|c|c|}
\hline Variable & No. $(\%) /$ median (range) \\
\hline Age (yr) & $56(22-75)$ \\
\hline Male gender & $7(35.0)$ \\
\hline \multicolumn{2}{|l|}{ Operation type } \\
\hline Left-sided pancreatectomy & $10(50.0)$ \\
\hline $\begin{array}{l}\text { Spleen-saving vessel-preserving } \\
\text { distal pancreatectomy }\end{array}$ & 5 \\
\hline Splenectomy & 5 \\
\hline Subtotal pancreatectomy & 4 \\
\hline $\begin{array}{l}\text { Extended pancreatectomy with } \\
\text { gastric resection }\end{array}$ & 1 \\
\hline $\begin{array}{l}\text { Hepatectomy (including radical } \\
\text { cholecystectomy) }\end{array}$ & $7(35.0)$ \\
\hline Triple bypass & $1(5.0)$ \\
\hline Gastric resection & $1(5.0)$ \\
\hline Cholecystectomy & $1(5.0)$ \\
\hline Operation time (min) & $445(80-825)$ \\
\hline Tumour size $(\mathrm{cm})$ & $4.0(1.2-7.5)$ \\
\hline Open conversion & $1(5.0)$ \\
\hline Blood loss (mL) & $350(0-1,200)$ \\
\hline Postoperative stay (day) & $5.5(3-22)$ \\
\hline Readmission & $2(10.0)$ \\
\hline Postoperative morbidity & $5(25.0)$ \\
\hline Major morbidity* & $2(10.0)$ \\
\hline
\end{tabular}

*> Grade II on the Clavien-Dindo classification.

neoplasm but was found to have a pseudocyst on final histology. Patient 17 presented with obstructive jaundice and underwent endoscopic retrograde cholangiopancreatography (ERCP) and stenting. He was diagnosed with Mirizzi's syndrome on ERCP. He subsequently underwent RAL cholecystectomy and was found to have chronic cholecystitis, with adhesions around Calot's triangle but no definite evidence of Mirizzi's syndrome.

Patients had a median age of 56 (range 22-75) years and $7(35.0 \%)$ were men. The median tumour size was 4.0 (range $1.2-7.5) \mathrm{cm}$. The difficulty of hepatectomies was graded as low in one patient, intermediate in four patients and high in two patients. The median operation time was 445 (range 80-825) minutes and median blood loss was 350 (range 0-1,200) mL. There was $1(5.0 \%)$ elective conversion to open surgery (Patient 7), as the large pancreatic body tumour was adherent to the coeliac axis and could not be dissected using robotic surgery. Overall, 5 (25.0\%) patients experienced postoperative morbidity and $2(10.0 \%)$ patients had major morbidity > Grade II on the Clavien-Dindo classification. Both these patients had Grade IIla morbidities that were found to be Grade B pancreatic fistulas after pancreatectomies that required percutaneous drainage. The other three patients with postoperative morbidity experienced minor morbidities, including Grade A bile leak that resolved spontaneously after Segment $\mathrm{V}$ liver resection, postoperative ileus and postoperative chyle leak. Three patients experienced purely biochemical Grade A pancreatic fistulas that were asymptomatic and not considered a morbidity in this study. Overall, there were
$5(50.0 \%)$ pancreatic fistulas in the ten patients who underwent RAL pancreatectomies, of which $2(20.0 \%)$ were clinically significant Grade B fistulas. There were no reoperations and no 30-day/in-hospital mortalities. The median postoperative stay was 5.5 (range 3-22) days. There were two readmissions in the two patients with Grade B pancreatic fistulas, for percutaneous drainage.

\section{DISCUSSION}

RAL surgery has been increasingly applied for complex laparoscopic procedures since the 1990s. ${ }^{(34)}$ However, although it is now widely used for complex urological and gynaecological procedures, its application in the field of HPB surgery remains extremely limited. ${ }^{(35)}$ The first series of RAL hepatectomies and pancreatectomies was reported by Giulianotti et al in 2003. ${ }^{(19)}$ Subsequently, only a few relatively large series ${ }^{(36)}$ have been reported in the literature. These recent reports have demonstrated the effectiveness of RAL surgery for pancreatectomy, hepatectomy, complex biliary constructions and even vascular reconstructions. ${ }^{(34}$

Despite its many advantages, however, RAL HPB surgery remains a technically challenging procedure with significant challenges, especially during the initial learning phase. This is illustrated by several recent series, even from high-volume tertiary centres that have reported their experience with RAL HPB surgery. Hanna et al from the Carolinas Medical Center, Charlotte, USA, reported their first experience of 77 patients who underwent various RAL HPB procedures by a single surgeon over a period of six years. ${ }^{(34)}$ They reported 24 conversions, of which $14(18.2 \%)$ were conversions to open procedures. Another recent large series on RAL distal pancreatectomies from the Memorial Sloan Kettering Cancer Center, New York, USA, reported that open conversions were required in 14 (37.8\%) out of 37 robotic distal pancreatectomies. ${ }^{(36)}$

In our study, the open conversion rate was $5.0 \%$, which is comparable to outcomes from highly experienced centres ${ }^{(17,18,34)}$ despite this being our early experience with RAL HPB surgery. We postulate that this can be attributed to two main reasons. Firstly, our team of surgeons had a large amount of collective experience with open complex and conventional laparoscopic HPB surgery before embarking on robotic surgery. Experts have frequently reiterated ${ }^{(8)}$ that a strong foundation in open HPB surgery, ideally coupled with advanced laparoscopic skills, is required before attempting complex laparoscopic HPB surgery. Furthermore, although some surgeons propose that the robotic platform is ideal and simpler for open surgeons who are keen to embark on minimally invasive surgery compared to conventional laparoscopy, ${ }^{(37)}$ we, like several others, found that the learning curve for RAL surgery is even shorter for surgeons already proficient in advanced laparoscopy. Surgeons who are already familiar with advanced laparoscopy can easily transfer the acquired skill sets, such as operation room setup, trocar placement, the magnified view of the surgical field seen through a television monitor and the unique operative approaches associated with minimally invasive surgery, with only minor 
modifications. Low conversion rates have also been reported by other investigators already proficient with advanced laparoscopic HPB surgery when they embarked on robotic HPB surgery. ${ }^{(35,38)}$ Chan et al from Hong Kong reported only one open conversion in their initial experience with 55 robotic surgical procedures. ${ }^{(35)}$

Secondly, appropriate patient selection is of utmost importance. Surgeons starting RAL HPB surgery should select cases that are relatively straightforward and appropriate for their level of experience. However, unlike some groups who proposed performing RAL HPB surgery with basic procedures, such as cholecystectomies, ${ }^{(37)}$ we began performing RAL surgery in moderately difficult cases, such as minor hepatectomies and distal pancreatectomies. This was possible because we had already acquired a relatively large amount of experience with $\mathrm{LH}$ and LP prior to embarking on the RAL HPB surgery programme. Furthermore, in our opinion, it would be extremely difficult to justify the cost of using the robot for such straightforward procedures as cholecystectomies. Nonetheless, although a few difficult hepatectomies were performed, we did not attempt any pancreaticoduodenectomies or central pancreatectomies during our initial experience, as we felt these procedures were too complex and risky to attempt during the initial stages of our learning curve. Limiting open conversion rates after minimally invasive surgery is important, as patients would then no longer enjoy the benefits associated with laparoscopy and may potentially have worse outcomes. ${ }^{(1,39)}$ Nonetheless, it is important to reiterate the long-held surgical dictum of laparoscopic surgery that surgeons should not be afraid to convert to the open procedure when required for patient safety. ${ }^{(40)}$ Indeed, conversion should never be regarded as a morbidity and timely conversion can be advantageous to patients.

In our opinion, RAL surgery is currently not competitive but simply an extension of conventional laparoscopic surgery. It is an extremely useful tool to add to the armamentarium of any surgeon practising advanced laparoscopic surgery, such as major HPB surgeries. The main advantages of the robot are the high-quality three-dimensional magnified view, stabilised control of the robotic instruments allowing fine stable movements and superior dexterity from the $7^{\circ}$ of freedom of movement due to the highly innovative Endowrist. These translate to superior steadiness, precision and dexterity, which allow fine accurate dissection and suturing in tight spaces. The clinical applicability of this in HPB surgery is mainly for fine, stable dissection and for complex reconstruction of bilioenteric and pancreaticoenteric anastomoses. ${ }^{(19,35)}$ In the current series, we performed a hepaticojejunostomy in a patient with advanced pancreatic cancer and found that the creation of the anastomoses was made simpler, as accurate sutures and tying of knots were simplified by the Endowrist. The improved dexterity and stability of the Endowrist also allowed more precise dissection and fine suturing during other procedures, such as spleen-preserving pancreatectomies, ${ }^{(27)}$ and for control of bleeding veins in tight spaces during hepatectomies. ${ }^{(28)}$

Presently, there is some low-level clinical evidence from small retrospective series that suggests that RAL surgery may be superior to conventional laparoscopic surgery for complex HPB operations. Tsung et al reported that LH performed via robotic assistance was associated with a significantly higher proportion of surgeries completed laparoscopically. ${ }^{(18)}$ Several authors have also demonstrated that laparoscopic distal pancreatectomies performed with robotic assistance were associated with increased splenic preservation compared to conventional laparoscopy. ${ }^{(7,41)}$ However, it is imperative to note that in general, most comparative studies $^{(16,38,42,43)}$ have demonstrated no significant difference in key outcomes between robotic and conventional laparoscopic HPB surgeries.

The main barrier today to the widespread use of RAL surgery is the increased cost associated with the procedure. ${ }^{(44)}$ As many studies show no difference in outcomes between robotic surgery and conventional laparoscopy, justification for its routine use is difficult. Furthermore, relatively few surgeons worldwide have regular access to this technology due to the high cost of purchasing and maintaining the robot. Hence, given their lack of familiarity with the system, few surgeons are willing to attempt RAL operations. Nonetheless, it is important to point out that as with all new technological applications or devices today, costs are likely to decrease exponentially with increased adoption. Moreover, more recent studies ${ }^{(45,46)}$ seem to suggest that for highly complex procedures such as pancreaticoduodenectomies, RAL was associated with lower open conversion rate and morbidity compared to conventional laparoscopy.

In conclusion, our initial experience with RAL HPB surgery demonstrated that it is feasible and can be performed safely. In our opinion, robotic assistance is complementary, and not competitive, with conventional laparoscopy, especially when performing certain complex tasks that may often be required during laparoscopic HPB surgery. Its application to laparoscopic HPB surgery may further expand minimally invasive indications to even more technically challenging operations. Further evaluation with clinical trials in larger patient cohorts is needed to determine whether it is superior and advantageous when compared to conventional laparoscopy and especially whether the increased cost justifies its routine application.

\section{REFERENCES}

1. Goh BK, Chan CY, Wong JS, et al. Factors associated with and outcomes of open conversion after laparoscopic minor hepatectomy: initial experience at a single institution. Surg Endosc 2015; 29:2636-42.

2. Goh BK, Chui $\mathrm{CH}$, Yap TL, et al. Is early laparoscopic appendectomy feasible in children with acute appendicitis presenting with an appendiceal mass? A prospective study. J Pediatr Surg 2005; 40:1134-7.

3. Purkayashtha S, Tilney HS, Georgiou, et al. Laparoscopic cholecystectomy vs mini-laparotomy cholecystectomy: a meta-analysis of the randomised control trials. Surg Endosc 2007; 21:1294-300.

4. Goh BK, Tan YH, Yip SK, Eng PH, Cheng CW. Outcome of patients undergoing laparoscopic adrenalectomy for primary hyperaldosteronism. JSLS 2004; 8:320-5.

5. Koh YX, Chok AY, Zheng HL, et al. A systematic review and meta-analysis comparing laparoscopic versus open gastric resections for gastrointestinal stromal tumors of the stomach. Ann Surg Oncol 2013; 20:3549-60.

6. Law WL, Lee YM, Choi HK, Seto CL, Ho JW. Impact of laparoscopic resection for colorectal cancer on operative outcomes and survival. Ann Surg 2007; 245:1-7.

7. Goh BK, Chan CY, Soh HL, et al. A comparison between robotic-assisted laparoscopic distal pancreatectomy versus laparoscopic distal pancreatectomy. Int J Med Robot 2016

8. Buell JF, Cherqui D, Geller DA, et al. The international position on laparoscopic liver surgery. the Louisville statement, 2008. Ann Surg 2009; 250:825-30. 
9. Wakabayashi G, Cherqui D, Geller DA, et al. Recommendations for laparoscopic liver resection: a report from the second international consensus conference held in Morioka. Ann Surg 2015; 261:619-29.

10. Venkat R, Edil BH, Schulick RD, et al. Laparoscopic distal pancreatectomy is associated with significantly less overall morbidity compared to the open technique: a systematic review and meta-analysis. Ann Surg 2012; 255:1048-59.

11. Wilson EB. The evolution of robotic general surgery. Scand J Surg 2009; 98:125-9

12. Lanfranco AR, Castellanos AE, Desai JP, Meyers WC. Robotic Surgery: a current perspective. Ann Surg 2004; 239:14-21.

13. Vigano L, Laurent A, Tayar C, et al. The learning curve in laparoscopic liver resection: improved feasibility and reproducibility. Ann Surg 2009; 250:772-82.

14. Zhang J, Wu WM, You L, Zhao YP. Robotic versus open pancreatectomy: a systematic review and meta-analysis. Ann Surg Oncol 2013; 20:1774-80.

15. Ho CM, Wakabayshi G, Nitta H, et al. Systematic review of robotic liver resection. Surg Endosc 2013; 27:732-9.

16. Strijker M, van Santvoort HC, Besselink MG, et al. Robot-assisted pancreatic surgery: a systematic review of the literature. HPB (Oxford) 2013; 15:1-10.

17. Zureikat AM, Moser J, Boone BA, et al. 250 robotic pancreatic resections: safety and feasibility. Ann Surg 2013; 258:554-9.

18. Tsung A, Geller DA, Sukato DC, et al. Robotic versus laparoscopic hepatectomy: a matched comparison. Ann Surg 2014; 259:549-55.

19. Giulianotti PC, Coratti A, Angelini M, et al. Robotics in general surgery: personal experience in a large community hospital. Arch Surg 2003; 138:777-84.

20. Wang E, Kow AW, Chan CY, Liau KH, Ho CK. Starting a laparoscopic hepatectomy programme. Singapore Med J 2009; 50:354-9.

21. Das De S, Kow AW, Liau KH, et al. Novel approach to laparoscopic resection of tumours of the distal pancreas. ANZ J Surg 2009; 79:288-93.

22. Tan KK, Shelat VG, Liau KH, Chan CY, Ho CK. Laparoscopic common bile duct exploration: our first 50 cases. Ann Acad Med Singapore 2010; 39:136-42.

23. Shelat VG, Chan CY, Liau KH, Ho CK. Laparoscopic exploration can salvage failed endoscopic bile duct stone extraction. Singapore Med J 2012; 53:313-7.

24. Leong WQ, Ganpathi IS, Kow AW, Madhavan K, Chang SK. Comparative study and systematic review of laparoscopic liver resection for hepatocellula carcinoma. World J Hepatol 2015; 7:2765-73.

25. Goh BK, Chan CY, Lee SY, et al. Laparoscopic liver resection for tumors in the left lateral liver section. JSLS 2016; 20:pii: e2015.00112.

26. Soh YF, Kow AW, Wong KY, et al. Perioperative outcomes of laparoscopic and open distal pancreatectomy: our institution's 5-year experience. Asian J Surg 2012; 35:29-36

27. Goh BK, Wong JS, Chan CY, et al. First experience with robotic spleen-saving vessel-preserving distal pancreatectomy in Singapore: report of three consecutive cases. Singapore Med J 2016; 57:464-9.

28. Kam JH, Goh BK, Chan CY, et al. Robotic hepatectomy: initial experience of a single institution in Singapore. Singapore Med J 2016; 57:209-14.

29. Strasberg SM. Nomenclature of hepatic anatomy and resection: a review of Brisbane 2000 system. J Hepatobiliary Pancreat Surg 2005; 12:351-5.

30. Ban $\mathrm{D}$, Tanabe $\mathrm{M}$, Ito $\mathrm{H}$, et al. A novel difficulty scoring system for laparoscopic liver resection. J Hepatobiliary Pancreat Sci 2014; 21:745-53.

31. Hartwig W, Vollmer CM, Fingerhut A, et al; International Study Group on Pancreatic Surgery. Extended pancreatectomy in pancreatic ductal adenocarcinoma: definition and consensus of the International Study Group for Pancreatic Surgery (ISGPS). Surgery 2014; 156:1-14.

32. Dindo D, Demartines N, Clavien PA. Classification of surgical complications: a new proposal with evaluation in a cohort of 6336 patients and result of a survey. Ann Surg 2004; 240:205-13.

33. Bassi C, Dervenis C, Butturini G, et al; International Study Group on Pancreatic Fistula Definition. Postoperative pancreatic fistula: an international study group (ISGPF) definition. Surgery 2005; 138:8-13.

34. Hanna EM, Rozario N, Rupp C, et al. Robotic hepatobiliary and pancreatic surgery: lessons learned and predictors for conversion. Int J Med Robot 2013; 9:152-9.

35. Chan OC, Tang CN, Lai EC, Yang GP, Li MK. Robotic hepatobiliary and pancreatic surgery: a cohort study. J Hepatobiliary Pancreat Sci 2011; 18:471-80.

36. Lee SY, Allen PJ, Sadot E, et al. Distal pancreatectomy: a single institution's experience in open, laparoscopic, and robotic approaches. J Am Coll Surg 2015; 220:18-27

37. Wakabayashi G, Sasaki A, Nishizuka S, Furukawa T, Kitajima M. Our initial experience with robotic hepato-biliary-pancreatic surgery. J Hepatobiliary and Pancreat Sci 2011; 18:481-7.

38. Qui J, Chen S, Chengyou D. A systematic review of robotic-assisted liver resection and meta-analysis of robotic versus laparoscopic hepatectomy for hepatic neoplasms. Surg Endosc 2016; 30:862-75.

39. Troisi RI, Montalti R, Van Limmen JG, et al. Risk factors and management of conversions to an open approach in laparoscopic liver resection: analysis of 265 consecutive cases. HPB (Oxford) 2014; 16:75-82.

40. Costi R, Scatton O, Haddad L, et al. Lessons learned from the first 100 laparoscopic liver resections: not delaying conversion may allow reduced blood loss and operative time. J Laparoendosc Adv Surg Tech A 2012; 22:425-31.

41. Kang CM, Kim DH, Lee WJ, Chi HS. Conventional laparoscopic and robotassisted spleen-preserving pancreatectomy: does da Vinci have clinical advantages? Surg Endosc 2011; 25:2004-9.

42. Montalti R, Berardi G, Patriti A, Vivarelli M, Troisi RI. Outcomes of robotic vs laparoscopic hepatectomy: a systematic review. World J Gastroenterol 2015; 21:8441-51.

43. Pelletier JS, Gill RS, Shi X, Birch DW, Karmali S. Robotic-assisted hepatic resection: a systematic review. Int J Med Robot 2013; 9:262-7.

44. Turchetti G, Palla I, Pierotti F, Cuschieri A. Economic evaluation of da Vinciassisted robotic surgery: a systematic review. Surg Endosc 2012; 26:598-606.

45. Zureikat $\mathrm{AH}$, Borrebach J, Pitt HA, et al. Minimally invasive hepatopancreatobiliary surgery in North America: an ACS-NSQIP analysis of predictors of conversion for laparoscopic and robotic pancreatectomy and hepatectomy. HPB (Oxford) 2017; 19:595-602.

46. Ricci C, Casadei R, Taffurelli G, etal. Minimally invasive pancreaticoduodenectomy: what is the best "choice"? A systematic review and network meta-analysis of non-randomized comparative studies. World J Surg 2018; 42:788-805. 